\title{
Adenoidektominin Orta Kulağa Etkisi: Preoperatif ve Postoperatif Timpanogram ve Otoskopik Değerlendirmenin Karșılaștırılması
}

\author{
Effects of Adenoidectomy on the Middle Ear: Comparison of Preoperative and Postoperative Tympanograms and \\ Otoscopic Evaluations
}

Selmin Karataylı-Özgürsoy', Mustafa Mert Bașaran'1, Șefik Halit Akmansu', Sinan Kocatürk'

Ufuk Üniversitesi Tıp Fakültesi, Kulak Burun Boğaz ABD, Ankara Türkiye

Geliș Tarihi: 23.07.2016• Kabul Tarihi: 24.08.2016

İletișim

Yrd. Doç. Dr. Selmin Karatayli-Ozgursoy

E-mail: selminkrt@hotmail.com

Tel: 05326159621

Tıp Fakültesi, Kulak Burun Boğaz ABD, Ankara, Türkiye, 06080

Amaç: Adenoidektomi özellikle pediatrik yaș grubunda kulak burun boğaz hekimleri tarafından en sık kullanılan cerrahi yöntemlerden olup, endikasyonları genellikle ağzı açık solunum, horlama, hiponazalite, sık kulak enfeksiyonudur. Adenoid doku ile östaki tüpünün anatomik lokalizasyonunun yakınlığı nedeniyle, adenoid dokunun hipertrofisi ve enfeksiyonu; östaki tüp disfonksiyonuna, tıkanıklığa ve sonuçta orta kulak effüzyonlarına yol açabilmektedir. Biz bu retrospektif çalıșmada, adenoid hipertrofisinin orta kulak basıncı üzerine etkisini; adenoidektomi öncesi ve sonrası otoskopik muayene ve timpanometrilerini karșılaștırarak değerlendirmeyi hedefledik.

Gereç ve Yöntem: Çalıșmamıza, adenoidektomi ve adenotonsillektomi yapılan ve kulaklarına hiçbir girișimde bulunulmayan toplam 110 hasta (220 kulak) dahil edilmiș, ve hastaların anamnezleri, nazal endoskopik muayene notları, operasyon notları ile preoperatif ve postoperatif 6 . aydaki otoskopik muayene ve timpanometrik incelemeleri not edilmiștir.

Bulgular: Çalıșmamıza, preoperatif nazal endoskopik muayene ile koanayı en az $\% 80$ dolduran adenoid hipertrofiye sahip hastalar dahil edilmiștir. Preoperatif dönemde tip $B$ ve $C$ olan ve orta kulakta efüzyon ișaret eden kulakların ( $n=63) \% 85,71$ oranında $(n=54)$, düzelme sağladığı görülmüștür. Dört yașında veya daha küçük olan çocuklar ile 4 yașından büyük çocukların preoperatif veya postoperatif timpanogramları karșılaștıııldığında, iki grup arasında anlamlı bir fark elde edilmemiș, her iki yaș grubunun timpanogramlarında da postoperatif anlamlı düzelme kaydedilmiștir.

Sonuç: Sonuç olarak, hastaların büyük oranında, sadece adenoidektomi ile, orta kulaktaki efüzyon azalabilmekte, ve ileride olusabilecek efüzyonlu otitis media komplikasyonlarının, veya ventilasyon tüp gerekliliğin önüne geçilebilmektedir. Ileride yapılacak prospektif ve kontrollü çalıșmalar ile, daha güvenilir bulgular elde edilebilir.

Anahtar Sözcükler: Adenoidektomi, Efüzyon/u Otitis Media, Timpanometri, Otoskopik Değerlendirme, Efüzyonlu Otitis Media

Aim: Adenoidectomy is one of the most common surgeries performed by otolaryngologists especially in pediatric patients where the indications are generally mouth breathing, snoring, hyponasality and recurrent or persistent otitis media. Because of close localization between adenoid tissue and eustachian tube, adenoid hypertrophy and infection may cause eustachian tube disfunction, obstruction and as a result middle ear effusion. In our retrospective study, we aimed to compare adenoid hypertrophy's affect to middle ear pressure preoperatively and postoperatively by using otoscopic examination and tympanometry.

Meterial And Methods: In our study 110 patients (220 ear) that underwent adenoidectomy or adenotonsillectomy without any attempt to ears were included and patients' medical histories, nasal endoscopic examinations, operation notes and preoperative and postoperative 6th month otoscopic examinations and tympanometric results were recorded.

Results: Patients who had adenoid hypertrophy filling at least $80 \%$ of choana in their preoperative endoscopic examination were included in our study. Ears that were type $B$ and $C$ preoperatively $(n=63)$, indicating middle ear effusion, were improved in $85.71 \%(n=54)$ of cases. When preoperative and postoperative tympanograms of patients older than 4 years old and 4 year old and/or younger patients compared, there was no significant statistical difference; and a significant improvement was seen in both age groups.

Conclusion: As a result, in major amount of patients, with only adenoidectomy, middle ear effusions may improve, and future complications of otitis media with effusion or necessity of ventilation tubes may be prevented. More reliable findings can be gained with future prospective and controlled studies.

Key Words: Adenoidectomy, Otitis Media With Effusion, Tympanometry, Otoscopic Evaluation, Otitis Media With Effusion

Waldeyer halkasinın elemanları; vücudun antijenleri ilk olarak karşıladığı lenfoid dokulardan oluşur (1). Waldeyer hakasının önemli bir elemanı olan ve nazofarenks posterior duvarında yer alan adenoid dokunun, enfeksiyon ve/veya hipertrofi durumunda; lokalizasyonu nedeniyle otitis media etyopatogenezinde rol oynadığı bilinmektedir (2).

Nazofarenkste yer alan bir diğer yapı olan östaki tüpünün görevleri; orta kulak havalanmasını sağlayarak atmosferik basıncı orta kulak basıncı ile dengelemek ve mukosilier temizle- 
medir. Östaki tüpünün disfonkisyonu; timpan membran retraksiyonuna ve ilerleyen dönemlerde de iletim tipi işitme kaybına yol açmaktadır (3).

Adenoid doku ile östaki tüpünün anatomik lokalizasyonunun yakınlı̆̆1 nedeniyle, adenoid dokunun hipertrofisi ve enfeksiyonu; östaki tüp disfonksiyonuna, tıkanıklığa ve sonuçta orta kulak effüzyonlarına yol açabilmektedir (4).

Adenoid hipertrofisinin tanısını koyabilmek için palpasyon, ayna ile görüntüleme, akustik rinometri, rinomanometri, radyolojik yöntemler ve nazal endoskopi kullanılmaktadır (5).

Nazal endoskopi adenoid hipertrofisi tanisı konmasinda altın standard olarak kabul edilmektedir (6). Nazal endoskopi uygun şartlarda ve uygun endoskop kullanıldığında güvenilir, güvenli, kolay tolere edilen ve dinamik bir tanısal yöntemdir (7).

Adenoidektomi özellikle pediatrik yaş grubunda kulak burun boğaz hekimleri tarafindan en sik kullanılan cerrahi yöntemlerden olup, endikasyonları genellikle ağzı açık solunum, horlama, hiponazalite, sik kulak enfeksiyonudur (8).

Effüzyonlu otitis media; kulak enfeksiyonuna dair bulgu veya semptomlara yol açmadan, orta kulakta oluşan sıv1 toplanmasidır. Belirti vermemesinden ötürü, daha çok hastalığın ilerleyen dönemlerinde işitme kaybı ve gelişme geriliği ve mental retardasyona yol açabilmektedir (9). Tanıda, otoskopik muayenenin önemi büyüktür; ancak hastaların genellikle bebek ve çocuk yaşta olması, ve muayene sırasında ağlamasından dolayı, siklikla timpan membran konjesyone görülebilmekte ve hekimi yaniltabilmektedir (10).

Timpanometri, orta kulak hastalıklarında rutin olarak kullanilan tanısal bir testtir (3). Orta kulak basincı ve östaki tüp fonksiyonu hakkında bilgi veren bu testin sonucunun değerlendirilmesinde, modifiye Jerger siniflaması kullanılmaktadir (9).

Biz bu retrospektif çalşsmada, adenoid hipertrofisinin orta kulak basincı üzerine etkisini; adenoidektomi öncesi ve sonrası otoskopik muayene ve timpanometri ile değerlendirmeyi hedefledik.

\section{Gereç ve Yöntem}

Çalışmamız Ufuk Üniversitesi Tıp Fakültesi Etik kurul onayı alınmasinın ardından başlamıştır (30/04/2015-6). Bu çalışmada, Ocak 2014 ile Temmuz 2015 yıllar1 arasında Ufuk Üniversitesi Tıp Fakültesi Dr. Rıdvan Ege Hastanesi'nde adenoidektomi ve adenotonsillektomi yapilan hastalarin dosyas1 retrospektif olarak incelenmiştir. Çalışmamıza toplam 110 hasta (220 kulak) dahil edilmiş, ve hastaların anamnezleri, nazal endoskopik muayene notları, operasyon notları ile preoperatif ve postoperatif 6 . aydaki otoskopik muayene ve timpanometrik incelemeleri not edilmiştir.

Adenoidektomi veya adenotonsillektomi sirasinda veya daha evvel miringotomi yapılan veya ventilasyon tüpü takılan hastalar çalışma dışı bırakılmıştır. Ayrica kraniofasial anomalisi, sistemik hastalığ1, koanal atrezisi, kulak zar1 perforasyonu mevcut olan, yakın zamanda kulak akıntısı geçiren, ve kulak anomalisi olan hastalar çalışma d1şında bırakılmıştır.

Operasyon öncesi her hastaya nazal endoskopik muayene yapılmıştır. Nazal endoskopik muayene; 2,4 $\mathrm{mm} 0$ derece nazal rijid (Storz, Tuttlingen Almanya) veya fleksibl nazofaringoskopi (Lut, Denzlingen, Almanya) eşliğinde yapılmıştır. Adenoid dokusu ile koana açıklığının oranı yüzdesel olarak not edilmiştir. Çalışmamıza, preoperatif nazal endoskopik muayene ile koanay1 en az $\% 80$ dolduran adenoid hipertrofiye sahip hastalar dahil edilmiștir.

Otoskopik muayene, preoperatif ve postoperatif 5-7. ayda yapılmış olup; timpan membran normal, mat veya retrakte olarak not edilmiştir. Retrakte olan 5 kulağın 4'ü Sade kalsifikasyonuna göre Evre 1, 1'i ise Evre 2 idi.

Timpanometri, aynı odyometrist tarafindan Interacoustics AZ 26 (Assens, Danimarka) ile $226 \mathrm{~Hz}$ frekansa sahip olan prob kullanılarak yapılmıştır. Timpanometri, hastalara preoperatif 1 gün önce ve postoperatif 5-7. ayda yapılmıştır.

Timpanogram sonuçları Jerger sınıflamasi kullanilarak tip A, B ve C olarak ay- rılmıştır. Basınçlar ayrıca not edilmiştir. Tip A normal komplians, tip B efüzyonlu otitis media, tip C östaki disfonksiyonu veya efüzyonlu otitis medianın erken safhası olarak öngörülmektedir (9).

Preoperatif takipler 3 ay süre ile yapılmış olup, bu süre içerisinde efüzyonlu otit bulgusu gerilemeyen hastalar (timpanogramda tip B veya otoskopik muayenede mat görünüm), uygun kategorilerde ele alınmıştır. Bu retrospektif çalışmaya alınan hastalar, cerrah ve ailenin ortak kararı ile ventilasyon tüpü takılmayan ve sadece adenoidektomi uygulanan hastalardır ve postoperatif dönemde efüzyonlu otitin gerileyip gerilememesi bakımından sıkı takibe alınmıslardır; adenoidektomi veya adenotonsillektomi sirasinda veya daha evvel miringotomi yapilan veya ventilasyon tüpü takılan hastalar ise çalışma dışı bırakılmıştır.

4 yaş ve altı ile 4 yaş üstü grupların preoperatif ve postoperatif efüzyonlu otitis media karşıllaştırılmasında ve erkekler ve kızların preoperatif ve postoperatif efüzyonlu otitis media siklığ1 karşılaştırılmasında, ki-kare testi kullanılmıștır.

\section{Sonuçlar}

Retrospektif olan bu çalışmamıza, kriterlere uyan toplam 110 hasta, 220 kulak dahil edilmiştir. Çalışmamıza 56 $(\% 51)$ adenoidektomi ve $54(\% 49)$ adenotonsillektomi operasyonu geçiren hasta dahil edilmiștir. 110 hastanın 53’ü $(\% 48,18)$ kız, 57’si $(\% 51,82)$ erkekti. En büyüğü 12, en küçüğü 3 yaşında olmak üzere yaş ortalaması 6,34 idi.

Kliniğimizde, deneyimli iki hekim tarafindan yapılan, preoperatif ve postoperatif otoskopik inceleme sonuçlar1; 220 kulak için, normal, retrakte ve mat olma dağılımı olarak Tablo 1'de verilmiştir.

Preoperatif ve postoperatif timpanometri sonuçları, tip A, tip B, ve tip C olarak Tablo 2'de verilmiştir. Preoperatif timpanometri değerlerinin ortalaması -73 dekapascal (dapa; en düşüğü -440; en yükseği 50) olarak ölçülmüsşür. Postoperatif 6. ayda tekrarlanan tim- 
panogram sonuçlarında; ortalamanın -33,46 dapa olduğu (en yükseği +56 dapa, en düşüğü -264 dapa) görülmüştür.

Preoperatif timpanogram tetkik sonucu tip B olarak gözlenen toplam 37 kulağın, postoperatif 6 . ayda yapilan timpanogram tetkiklerinde 30 kulakta tip A'ya; 2 kulakta tip C'ye dönüştüğü ve $5 \mathrm{k}$ ulakta ise tip $\mathrm{B}$ olarak kaldığ1 görülmüştür. Preoperatif dönemde tip C olan 26 kulağın 22 tanesi postoperatif dönemde tip A olarak görülmüş; 2 kulak tip $C$ olarak kalmış; 2 kulak ise tip B’ye dönmüștür. Bu bakımdan preoperatif dönemde tip B ve C olan ve orta kulakta efüzyon işaret eden kulakların ( $\mathrm{n}=63), \% 85,71$ oranında ( $n=54)$, düzelme sağladığı görülmüştür.

Ki kare testi uygulanarak, preoperatif ve postoperatif tip A timpanogram (normal kulak) sayıları ve preoperatif ve postoperatif tip B timpanogram (efüzyonlu otitli kulak) sayılar1 karșılaștırıldığında, her ikisinde de fark, istatiksel olarak anlamlı $(\mathrm{p}<0.05)$ bulunmuştur.

Hastalar, 4 yaş ve altı ve 4 yaş üstü olarak gruplandirıldıklarında, preoperatifpostoperatif timpanogram sonuçları tablo 3'te gösterilmiștir. 4 yaș ve altındaki toplam hasta sayısı 44, 4 yaş üstü toplam hasta sayısı ise 66 idi. Hem 4 yaş ve altı grupta, hem de 4 yaş üstü grupta ki kare testi uygulanarak, preoperatif ve postoperatif tip A timpanogram (normal kulak) sayllar1 ve preoperatif ve postoperatif tip B timpanogram (efüzyonlu otitli kulak) sayıları karşılaştırıldığında, her ikisinde de fark, istatiksel olarak anlamlı $(\mathrm{p}<0.05)$ bulunmuştur.

Ki kare testi uygulanarak her iki gruptaki pre-operatif tip A timpanogram sayıları karşılaştırıldığında $\mathrm{p}=0,24$; her iki gruptaki pre-operatif tip B timpanogram

say1lar1

Tablo 1: Preoperatif ve postoperatif kulak zarı muayenelerine göre dağılımı

\begin{tabular}{|l|l|l|}
\hline Kulak Zarı & Preoperatif & Postoperatif \\
\hline Normal & 155 & 208 \\
\hline Mat & 60 & 12 \\
\hline Retrakte & 5 & - \\
\hline
\end{tabular}

Tablo 2: Preoperatif ve postoperatif timpanogram sonuçlarına göre dağı̆ımı

\begin{tabular}{|l|l|l|}
\hline Timpanogram Tipleri & Preoperatif & Postoperatif \\
\hline Tip A & 157 & 208 \\
\hline Tip B & 37 & 8 \\
\hline Tip C & 26 & 4 \\
\hline
\end{tabular}

Tablo 3: 4 yaş ve altı ile 4 yaş üstü hastaların preoperatif ve postoperatif timpanogram sonuçlarına göre dağılımı

\begin{tabular}{|l|l|l|l|l|}
\hline & \multicolumn{2}{|c|}{$\leq \mathbf{4}$ Yaș } & \multicolumn{2}{c|}{$>$ Y Yș } \\
\hline & Preoperatif & Postoperatif & Preoperatif & Postoperatif \\
\hline Tip A & 59 & 85 & 98 & 123 \\
\hline Tip B & 13 & 1 & 24 & 7 \\
\hline Tip C & 16 & 2 & 10 & 2 \\
\hline
\end{tabular}

Tablo 4: Kız ve erkek hastaların preoperatif ve postoperatif timpanogram sonuçlarına göre dağılımı

\begin{tabular}{|l|l|l|l|l|}
\hline & \multicolumn{2}{|c|}{ Kız } & \multicolumn{2}{c|}{ Erkek } \\
\hline & Preoperatif & Postoperatif & Preoperatif & Postoperatif \\
\hline Tip A & 78 & 100 & 79 & 108 \\
\hline Tip B & 13 & 4 & 24 & 4 \\
\hline Tip C & 15 & 2 & 11 & 2 \\
\hline
\end{tabular}

karşılaştııldığında $\mathrm{p}=0.51$; her iki gruptaki post-operatif tip A timpanogram sayıları karşılaştırıldığında $\mathrm{p}=0,27$; ve her iki gruptaki postoperatif tip B timpanogram sayıları karşılaştırıldığında ise $\mathrm{p}=0,11$ olup, hiçbirinde istatiksel olarak anlamlı $(\mathrm{p}<0.05)$ bir fark bulunmamıştır.

Cinsiyete göre pre- ve post- operatif timpanogram sonuçlar1 ise Tablo 4'te gösterilmiștir. Toplam kız hasta sayısı 53 ve erkek hasta sayısı 57 idi. Ki kare testi uygulanarak her iki gruptaki preoperatif tip A timpanogram sayları karşılaştırıldığında $\mathrm{p}=0.48$, pre-operatif tip B timpanogram saylları karşılaştırıldığında $\mathrm{p}=0.08$; her iki gruptaki post-operatif tip A timpanogram sayıları karşılaştırıldığında $\mathrm{p}=$ 0.89, her iki gruptaki post-operatif tip B timpanogram sayıları karşılaştırıldığında $\mathrm{p}=0.91$ olup, hiçbirinde istatiksel olarak anlamlı $(\mathrm{p}<0.05)$ bir fark bulunmamıştır.

\section{Tartıșma}

Adenoidektomi kulak burun boğaz hekimleri tarafindan en sik uygulanan operasyonlardan biridir (5). Adenoidektominin amac1, nazofarenkste darlığa yol açan veya sık enfeksiyona sebep olan lenfoid dokunun çıkarilmasıdır (2). Adenoidektominin genellikle ortalama 7 yaş grubunda yapıldı̆̆ı bildirilmiştir (11). Bizim çalışmamızda da hastalarımızın yaş ortalaması, benzer şekilde 6,34 idi. Çalışmamıza dahil olan erkek hasta sayısı, kız sayısından biraz fazla idi; efüzyonlu otitis media s1klığ ise, preoperatif tip B timpanogram sayıları karşılaştırıldığında istatiksel anlamlı fark elde edilmese de, erkeklerde daha fazla idi. Paradise ve arkadaşları (11) da, kızlar ve erkekler arasında, efüzyonlu otitis media sıklığ1 açısından anlamlı bir fark saptamamıştır.

Adenoid hipertrofisi, östaki tüpünün nasofarenksteki orifisini, anatomik lokalizasyonu nedeniyle, kısmen veya tamamen kapatabilmektedir. Bazı çalışmalarda, östaki tüpünün disfonksiyonu ile adenoid hipertrofisinin büyüklüğünün, birbiriyle orantılı olduğu bildirilmekte (12), bazı çalışmalarda ise (13), adenoid dokusu büyüklüğü 
ile timpanogram sonuçlarının korele olmadığ1, ve efüzyonlu otit etyopatogenezinde, adenoid dokusunun kitle etkisinden çok inflamasyon ve kontaminasyon kaynağ1 olması nedeniyle rol oynadığ1 belirtilmiştir. Bizim çalışmamızda, tüm hastaların adenoid büyüklükleri, fleksibl veya rijid pediatrik endoskop ile değerlendirilmiş ve çalışmamızda adenoid büyüklüğünün en az $\% 80$ olduğu vakalar seçilmiştir.

Dört yaşından büyük çocuklarda, hipertrofik ya da rekürren enfekte adenoid dokusu varsa adenoidektominin, efüzyonlu otitis media tedavisinde ya da daha önceden ventilasyon tüpü takılmiş rekürren otitis media tedavisinde etkili olduğu gösterilmiştir (14,15). İkibin onaltı y1linda güncellenen Amerikan Pediatri Akademi'sinin k1lavuzunda da, 4 yaşından küçük, efüzyonlu otiti olan çocuklarda, adenoid dokuya ait bir patoloji olmadı̆g sürece, adenoidektominin ilk tercih tedavi yöntemi olmadığ belirtilmiştir (16). Bu çalışmaların aksine, Kadhim ve arkadaşları (17), 10 yaş ve altındaki çocuklarda, ventilasyon tüpü tatbik edilirken, eş zamanlı adenoidektomi veya adenotonsillektominin, tekrarlayan ventilasyon tüpü tatbiki riskini azalttığını bildirmişlerdir. Adenoidektominin düşük komplikasyon riski ve hastanede yatış süresini uzatmayan bir cerrahi olmasi sebebiyle de efüzyonlu otit tedavisinde birinci basamak cerrahi olması gerektiğini belirtmişlerdir. Park da (18), retrospektif çalışmasında benzer sonuçlar elde etmiş, enfeksiyon odağını ortadan kaldırmak için, hipertrofi olsun ya da olmasın, adenoidektomi yapılmasının uygun olacağını bildirmiştir. Çalışmamızda 4 yaşında veya daha küçük olan çocuklar ile 4 yaşından büyük çocuklarin preoperatif veya postoperatif timpanogramları karşılaştırıldığında, iki grup arasında anlamlı bir fark elde edilmemiş, her iki yaş grubunun timpanogramlarında da anlamlı düzelme kaydedilmiştir. Vurgulamak gerekir ki, çalışmamıza dahil olan bütün çocuklarda adenoid hipertrofi mevcuttu, ve adenoid dokusu, koanayı en az \% 80 oranında kapatmaktaydı. Ek olarak, bu retrospektif çalışmada, sadece adenoidektomi veya adenotonsillektominin orta kulağa etkisi araştırılmış; aynı seansta veya daha evvel, miringotomi veya ventilasyon tüpü tatbiki yapılmış olan hastalar çalışma dışı bırakılmıştır. $\mathrm{Bu}$ çalışmaya dahil olan en küçük çOcuğun yaşının 3 olması; daha küçük çocukların kulağına aynı seansta girişim (miringotomi veya ventilasyon tüpü takılması) yapılmış olması sebebiyle bu çalışmaya alınmaması da sonuçlarımızda etkili olmuştur. Effüzyonlu otitis media; orta kulakta sıvı ile karakterize; çoğu zaman asemptomik olabilen ve pediatrik hastaların sıklıkla ağlamalarından dolayı yanlış teşhis konabilen bir hastalıktır (10). Tanı konmasinda anamnez, otoskopik muayene ile timpanogram önemli rol oynamaktadir. Timpanogram özellikle orta kulakta sıvı birikimi hakkında kantitatif bilgi vermektedir (19). -100 ile $-400 \mathrm{daPa}$ arasındaki değerler genellikle tip B timpanogram olarak değerlendirilir ve orta kulakta effüzyon göstergesi olarak kabul edilmektedir (20).

Adenoid hipertrofisinin östaki tüpü obstruksiyonuna yol açmasıyla oluşan orta kulaktaki negatif basincin, timpanogram bulgulariyla uyumlu olduğu bulunmuştur (21). Kocaturk ve arkadaşlarının (22) yaptığı bir çalışmada, preoperatif tip B timpanogram elde edilen 135 kulağın 118'inde $(\% 87,4)$ efüzyon tanısı intraoperatif olarak teyit edilmiştir. Preoperatif timpanogram sonuçlarının postoperatif sonuçlarla karşılaştırıldığında, adenoid hipertrofisinin, artmış negatif orta kulak basıncı ile ilişkili olduğu düşünülmektedir (12, 23-25). Effuzyonlu otitis media tedavisinde adenoidektominin etkinliği gösterilmiştir (26). Satish ve arkadaşlarının (9) çalışmasında da, adenoid hipertrofisi olan effuzyonlu otitis medialı hastalarda, işitmenin tedavisinde adenoidektominin basit ve etkili bir yöntem olduğu belirtilmiştir. Çalışmamızda da adenoidektomi veya adenotonsillektomi yapilan hastalarin preoperatif ve postoperatif timpano- metri karşılaştırıldığında, preoperatif dönemde tip B ve C olan ve orta kulakta efüzyon işaret eden kulakların, $\% 85,71$ oranında düzelme sağladığ1 görülmüştür. Yine preoperatif ve postoperatif timpanogramlar göz önüne alındığında, tip A (normal kulak) ve tip B (efüzyonlu otitli kulak) sayıları karșılaștırıldığında, her ikisinde de fark, istatiksel olarak anlamlı $(p<0.05)$ bulunmuş, postoperatif dönemde anlamlı düzelme izlenmiştir. $\mathrm{Bu}$ bakımdan efüzyonlu otitis media etyopatogenezinde adenoid hipertrofisinin, ve tedavisinde adenoidektominin büyük bir payı olduğu söylenebilir. Miringotomi ve/veya ventilasyon tüpü tatbikine karar verirken, bu işlemlerin yol açabileceği otore, persistan perforasyon, tüpün orta kulağa kaçması, geç dönemde miringoskleroz gibi olası komplikasyonları da göz ardı etmemek, kar/zarar oranına hasta bazında karar vermek gerekir (27, 28). Amerikan Kulak Burun Boğaz ve Baş Boyun Cerrahisi Akademisi'nin 2013'te yayınladığ1 'çocuklarda ventilasyon tüpü için klinik pratik rehberi'nde, 3 aydan uzun süren, unilateral veya bilateral efüzyonlu otit bulgusu olan ve işitme kaybının da eşlik ettiği çocuklarda, ailelerin de onamını alarak ventilasyon tüpü uygulanması önerilmiştir (29). İşitme testi yapılamadığı takdirde, aileden alınan hikaye önemlidir, televizyonu yüksek sesle dinleme, iletişim yetersizliği, okul başarısında düşme olup olmadığı sorgulanabilir. Rekürren otitlerde ise, prosedür esnasinda efüzyonlu otit bulgusu yok ise, tüp uygulanması önerilmemektedir.

Sonuç olarak, hastaların büyük oranında, sadece adenoidektomi ile, orta kulaktaki efüzyon azalabilmekte, ve ileride oluşabilecek efüzyonlu otitis media komplikasyonlarının, veya ventilasyon tüp gerekliliğin önüne geçilebilmektedir. Bu çalışmadan, adenoidektominin, ventilasyon tüpüne alternatif olduğu sonucu çıkartılmamalıdır, daha güvenilir sonuçlar için, prospektif ve kontrollü çalışmalara ihtiyaç vardır. 


\section{KAYNAKLAR}

1) Hellings P, Jorissen M, Ceuppens JL. The Waldeyer's ring. Acta Otorhinolaryngol Belg 2000; 54:237-241.

2) Bayindir T, Toplu Y, Kizilay A. Adenotonsiller Hipertrofinin Effüzyonlu Otitis Media Üzerine Etkileri. J Turgut Ozal Med Cent 2013;20: 92-95.

3) Chauhan B, Chauhan K. A Comparative Study of Eustachian Tube Functions in Normal and Diseased Ears with Tympanometry and Videonasopharyngoscopy. Indian J Otolaryngol Head Neck Surg 2013;65: 468-476.

4) Marseglia GL, Poddighe D, Caimmi D, et al. Role of adenoids andadenoiditis in children with allergy and otitis media. Curr Allergy Asthma Rep 2009;9:460-464.

5) Karataylı Özgürsoy S, Mulazimoğlu S, Akiner MN. Adenoid Hipertrofili Çocukların Değerlendirilmesi: Sefalografi ve Endoskopi'nin Karşılaştırılması. Ank. Üni. Tip Fak. Mecm. 2013; 66: 125-129.

6) Chisholm EJ, Lew-Gor S, Hajioff D, Caulfield H. Adenoid size assessment: a comparison of palpation, nasendoscopy and mirror examination. Clin Otolaryngol 2005; 30: 39-41.

7) Caylaklı F, Hizal E, Yilmaz I, et al Correlation between adenoid nasopharynx ratio and endoscopic examination of adenoid hypertrophy: a blind, prospective clinical study. International journal of pediatric otorhinolaryngology 2009; 73: 15-32.

8) Chien CY, Chen AM, Hwang CF, et al. The clinical significance of adenoidchoanae area ratio inchildren with adenoid hypertrophy. Int $\mathrm{J}$ Pediatr Otorhinolaryngol 2005;69:235-239.

9) Satish HS, Sarojamma, Kumar A Study role of Adenoidectomy in Otitis Media with Effusion. IOSR Journal of Dental and Medical Sciences 2013:4;20-24

10) Engel J, Anteunis L, Chenault M, et al. Otoscopic findings in relation to tympanometry during infancy. Eur Arch Otorhinolaryngol 2000;257:366-371.

11) Paradise JL, et al. OM in 2253 Pittsburgharea infants: Prevalence and risk factors during the first 2 years of life. Pediatrics 1997; 99:318

12) Alhady RA, Sharnoubi ME. Tympanometric findings in patients with adenoid hyperplasia, chronic sinusitis and tonsillitis. J Laryngol Otol 1984; 98: 671676.

13) Toros SZ, Kiliçoğlu G, Noşeri H, et al. Does adenoid hypertrophy really have effect on tympanometry? Int J Pediatr Otorhinolaryngol 2010;74:365-358.

14) Mattila PS. Role of adenoidectomy in otitis media and respiratory function. Curr Allergy Asthma Rep 2010;10:419424.

15) Casselbrant ML, Mandel EM, Rockette $\mathrm{HE}$, et al. Adenoidectomy for otitis media with effusion in 2-3-year-old children. Int J Pediatr Otorhinolaryngol 2009;73: 1718-1724.

16) Rosenfeld RM, Shin JJ, Schwartz SR, et al. Clinical Practice Guideline: Otitis Media with Effusion (Update). Otolaryngol Head Neck Surg 2016; Vol. 154(1S) S1-S41 .

17) American Academy of Pediatrics Subcommittee on Management of Acute Otitis Media. Diagnosis and management of acute otitis media. Pediatrics 2004;113:1451-1465.

18) Kadhim AL, Spilsbury K, Semmens JB, et al. Adenoidectomy for middle ear effusion: a study of 50,000 children over 24 years. Laryngoscope 2007;117:427-433.

19) Park K. Otitis media and tonsils-role of adenoidectomy in the treatment of chronic otitis media with effusion. Adv Otorhinolaryngol 2011;72:160-163.

20) Iacovou E, Vlastarakos PV, Ferekidis E, et al. Multi-frequency tympanometry: clinicalapplications for the assessment of the middle ear status. Indian J Otolaryngol Head Neck Surg 2013;65:283-287.

21) Gaihede M, Bramstoft M, Thomsen LT, et al. Accuracy of tympanometric middle ear pressuredetermination in secretory otitis media: dose-dependent overestimation related to the viscosity andamount of middle ear fluid. Otol Neurotol 2005;26:5-11.

22) Kindermann CA, Roithmann R, Lubianca Neto JF. Obstruction of the eustachian tube orifice and pressurechanges in the middle ear: are they correlated? AnnOtol Rhinol Laryngol 2008;117:425-429.

23) Kocaturk $S$, İncesulu $A$, Öztürk $E$, et al. Orta kulakta Effüzyon tespitinde Timpanogran Sonuçlarına $\mathrm{Ne}$ Kadar Güvenebiliriz? Otoskop; 2002;3:106-109.

24) Egeli E, Oghan F, Ozturk O, et al. Measuring the correlation between adenoidal-nasopharyngeal ratio (AN ratio) and tympanogram inchildren. Int J Pediatr Otorhinolaryngol 2005;69:229233.

25) Tuohimaa P, Tauno P. The effect of tonsillectomy and adenoidectomy on the intra-tympanic pressure. The Journal of Laryngology \& Otology 1987: 892-896.

26) Günel, C,Ermişler B, Basak HS. The effect of adenoid hypertrophy on tympanometric findings in children without hearing loss. Kulak burun bogaz ihtis. Derg. 2013: 334-338.

27) Cummings - Andrew F. Inglis Jr. George A. Gates Cummings Otolaryngology Head and Neck surgery,4th edition, Elsevier Mosby, 2005;4:4445-4464

28) Erkam Ü, Kocaturk S, Yardımcı S. Seröz Otitli Hastalarda Ventilasyon tüpü takılmadan önce orta kulağın serum fizyolojik ile irigasyonunun erken dönem postoperatif otorenin engellenmesi açısından oral antibiyotik kullanımı ile karşılaştırılması. Otoskop; 2003;2:64-68

29) Smillie I, Robertson S, Yule A, et al. Complications of ventilation tube insertion in children with and without cleft palate: a nested case-control comparison. JAMA Otolaryngol Head Neck Surg 2014;140:940-943.

30) Rosenfeld RM, Schwartz SR, Pynnonen $\mathrm{MA}$, et al. Clinical practice guideline: Tympanostomy tubes in children. Otolaryngol Head Neck Surg 2013;149:S1-35. 
